\title{
A casa do sol e o imaginário do tempo: ocupação criativa do legado de Hilda Hilst
}

\author{
The 'casa do sol' and the imaginarium of time: creative occupation \\ of Hilda Hilst's legacy
}

Alessandra Paula Rech ${ }^{1}$

Doutora em Letras - Literatura Brasileira, pela Universidade Federal do Rio Grande do Su (UFRGS), com tese sobre a obra de Hilda Hilst (Agudissimas Horas - Imagens do Tempo na Poesia de Hilda Hilst). Professora dos cursos de Comunicaçáa Social esosstaduaçao em Letras (UCS), desenvolve pesquisas sobre o Movimento Cartoneiro e a ocupação da Casa do Sol, essa última com financiamento do CNPa. E-mail: palavrear@gmail.com
RESUMO: 0 presente artigo resulta de pesquisa em andamento sobre o programa Residência Criativa, desenvolvido na Casa do Sol, onde viveu a escritora Hilda Hilst (1930-2004). O programa gera recursos para a manutenção do espaço, e possibilita a interação com o acervo, o compartilhamento de ideias e a continuidade da criação, em diálogo com sua memória. A abordagem toma como ponto de partida entrevistas com criadores e residentes, a fim de demonstrar a dimensão cultural da iniciativa, sua relevância e originalidade. Inclui, ainda, reflexões sobre a simbologia da casa, na linha de Bachelard. Partindo do pressuposto que essa forma de ocupação do patrimônio imaterial se insere num imaginário característico da pós-modernidade, o referencial teórico abarca Maffesoli e Bourriaud, a fim de refletir sobre as novas formas de relação no âmbito da cultura.

Palavras-chave: Hilda Hilst: Patrimônio imaterial; Economia criativa; Ocupação; Pós-modernidade.

ABSTRACT: The present article results from an ongoing research on the Creative Residence program, developed at Casa do Sol, where writer Hilda Hilst (1930-2004) lived. The program generates resources for the maintenance of space, and enables interaction with the collection, sharing of ideas and the continuity of creation, in dialogue with his memory. The approach takes as a starting point interviews with creators and residents to understand the cultural dimension of the initiative, its relevance and originality. Also includes reflections about the symbology of the house, in the line of Bachelard. Assuming that this form of occupation of the patrimony is inserted in an imaginary post-modern, the theoretical framework includes Maffesoli and Bourriaud to reflect on new ways of culture relationship.

Keywords: Hilda Hilst; Intangible heritage; Creative economy; Occupation; Postmodernity.
"Quando terra e flores eu sentir sobre o meu corpo, gostaria de ter ao meu lado tuas mãos. E depois, guardar meus olhos dentro delas." 


\section{Considerações iniciais}

Casa do Sol, lar da escritora paulista Hilda Hilst, em Campinas, oferece Aum caso exemplar de preservação da memória de forma dinâmica. Trata-se do programa Residência Criativa. Coerente com a trajetória da poeta, nascida em Jaú a 21 de abril de 1930 e falecida em 4 de fevereiro de 2004 que, em vida, fez da sua casa um reduto da intelectualidade, o programa sugere a criação continuada, em diálogo com a sua obra. No âmbito mercadológico, em que o cenário aponta para a presença hegemônica de grupos editoriais, as chamadas editoras transnacionais, pautando um consumo cultural de massa, com viés colonizante, iniciativas como o programa Residência Criativa denotam um desejo diferenciado de preservação do patrimônio e difusão da literatura, que se pode caracterizar como resistência a essa indústria.

O presente artigo tem como objetivo analisar como a proposta de ocupação da Casa do Sol exerce uma relação com a cultura típica da pósmodernidade. Para tanto, apresenta inicialmente, de forma resumida, a história do lugar e a relevância da Casa do Sol na obra de Hilda Hilst, no âmbito das ciências do imaginário, com Bachelard e Durand. A abordagem inclui entrevistas com idealizadores e residentes, no intuito de compreender o funcionamento prático da iniciativa. Por fim, aproxima o programa desenvolvido na casa às novas modalidades de interação com o patrimônio imaterial no contexto da pós-modernidade, refletindo sobre o conceito de ocupação artística, estética relacional e novas demandas de experiência cultural, tendo como principais referências Maffesoli e Bourriaud.

Com uma obra literária abrangente, resultado de mais de 45 anos de produção, Hilda Hilst está entre os maiores nomes mundiais da literatura em Língua Portuguesa. Rosenfeld (1970) sintetiza assim sua representatividade: "Hilda pertence ao raro grupo de artistas que conseguiu qualidade excepcional em todos os gêneros literários a que se propôs poesia, teatro e ficção".

A casa, no interior de São Paulo, foi construída por Hilda Hilst em 1965, em um sítio de propriedade da família. A intenção da escritora foi se distanciar da efervescência social na capital paulista para se dedicar à obra. Inspirada pela leitura de Carta a el Greco, do escritor grego Nikos Kazantzakis (1883-1957), Hilda se retira em 1966, aos 36 anos: "Me fechei nesta casa aos 33 ( $\mathrm{sic}$ ) anos para criar uma obra literária. Reneguei minha agitada vida social, namorados, família, tudo. Foi uma atitude radical. Me entreguei por inteiro", afirma, em entrevista (CHIODETTO, 2002, p. 150).

A moradia, então, torna-se um "espaço conventual criativo", na definição da amiga Olga Bilenky, artista plástica e, hoje, uma das administradoras do local. Olga frequentava a Casa nos anos 70, nela viveu entre 1991 e 1994 e voltou a residir ali a partir de 2012, com o tombamento.

Local de efervescência em torno da personalidade cativante de Hilda Hilst, a Casa do Sol foi frequentada por artistas que marcaram época, como os escritores Lygia Fagundes Telles e Caio Fernando Abreu, o escritor e editor José Luís Mora Fuentes e o maestro José Antônio de Almeida Prado. Por lá passaram, ainda, os físicos César Lattes e Mário Schenberg, que também foi crítico de arte. Marco na história cultural brasileira, portanto, o local é um atrativo àqueles que estudam ou apenas fruem o legado da escritora, uma vez que foi cenário não apenas para a gestação da monumental obra de Hilda Hilst, mas para boa parte da produção desse conjunto de referências nacionais do período.

A preservação e o acesso à Casa do Sol são importantes em dois aspectos: primeiramente, o patrimonial, o reduto físico ligado à biografia da escritora, como demonstrado até aqui. Paralelamente, como território simbólico, dada a importância da casa na obra literária de Hilda Hilst. 
Ainda em entrevista, Olga relata os primórdios da iniciativa:

O testamento da Hilda incluía herdeiros de sangue e a gente que vivia próxima a ela na casa. Parte desses herdeiros não entendiam a importância desse vínculo. E quando a Hilda faleceu começaram os trâmites para o inventário. Um sobrinho dela chegou aqui com o agente imobiliário, convicto em derrubar a casa. Foi um momento em que eu me ergui e falei - não pode! Aqui ninguém entra. Nessa mesma semana fui até São Paulo conversar com a Lygia Fagundes Telles. E ela me levou à Academia Brasileira de Letras. Lá foi unânime o apoio para o tombamento. Por meio do então presidente, o processo foi agilizado e conseguimos rapidamente defender a Casa do Sol da destruição que iria ocorrer em nome da ganância. Ia virar mais um terreno dentro de um condomínio fechado. (informação verbal) ${ }^{1}$

Garantido o tombamento, Olga pensou num destino condizente com a história da casa, convicta de que desejava mais que uma abertura formal ao público:

Quando me vi sozinha nessa casa, quis que ela continuasse movimentada como na época da Hilda. De certa forma, a ideia era dela, desde o começo, quando trazia seus amigos, quando acolhia outros escritores. Ela se realizava vendo nascer a produção desses artistas. E quando não gostava, era uma crítica implacável! (risos). A Residência Criativa é essa vida continuada. Houve o tombamento, há os objetos pela casa, mas nosso foco é o patrimônio imaterial, a vivência do espaço, não aquela situação em que as coisas ficam em redomas de acrílico... 0 desejo é de que a pessoa possa se integrar às rotinas da casa. Não estamos pensando em retorno financeiro, não há como seguir esse modelo acolhendo grandes grupos. 0 ideal são dois hóspedes por vez. (informação verbal) ${ }^{2}$

As ações de preservação e difusão da memória de Hilda Hilst hoje são desenvolvidas por meio do Instituto Hilda Hilst (IHH), e ajudam a manter

\footnotetext{
${ }^{1}$ BILENKY, Olga. Depoimento: [16 de fevereiro de 2016]. Entrevistadora: Alessandra Paula Rech. Campinas: Instituto Hilda Hilst, 2016.
}

2 Idem. sua sede, a Casa do Sol, localizada no bairro Parque Xangri-lá, e tombada como patrimônio histórico do município (resolução 119 - 02.04.2012). Além do pátio central, a área preservada inclui 10 mil metros quadrados de jardim e uma figueira centenária.

0 projeto Casa do Sol Viva abarca diversas iniciativas voltadas à difusão do legado da escritora, entre as quais se destacam Residência Criativa, que já recebeu mais de 100 residentes, entre poetas, escritores, acadêmicos, artistas, pesquisadores e tradutores, e o Teatro de Arena Casa do Sol, que apresenta espetáculos teatrais e leituras dramáticas de textos de Hilda Hilst e de outros autores nacionais e estrangeiros, para grupos de visitantes que muitas vezes têm conhecimento da obra de Hilda Hilst pela primeira vez, por meio desse teatro.

O Teatro de Arena é a forma encontrada hoje para o acolhimento de grupos, rompendo com o modelo tradicional de visitação que se daria em um típico "museu-casa de autor". Olga relata que, em parceria com o Serviço Social do Comércio (SESC), são trazidos grupos mediante agendamentos para conhecer a casa e assistir a uma peça de teatro. Um exemplo é o texto Osmo, representado pelo autor Donizeti Mazonas, nu, dentro de uma banheira na casa da escritora. "Causa estranheza a alguns dos visitantes, que chegam aqui sem fazer a menor ideia sobre a obra de Hilda Hilst", diz Olga. Estranhamento que pode ser considerado um estímulo criativo coerente com a trajetória da escritora: a casa como espaço de provocação cultural.

Na proposta de residência, os pesquisadores hospedam-se por períodos mínimos de quatro dias, a partir de aceitação do instituto, que prevê a contrapartida cultural. Esses hóspedes pagam uma diária (em torno de $\mathrm{R} \$ 100$ ) ou são financiados por órgãos de fomento à cultura e têm acesso à infraestrutura da casa, com autonomia para realização das suas refeições. Outra modalidade possível é a Residência Colaborativa, quando o custo 
é compensado por atividades necessárias à casa, como jardinagem, por exemplo. Em ambas as situações, o requisito para admissão do hóspede é muito amplo.

A ideia de um projeto de ocupação, de acordo com Olga, não é selecionar intelectualmente o visitante, apenas estabelecer que não se trata de um espaço "turístico". Como não há alternativas de lazer que costumam fazer parte de um hotel, como sala de tevê, playground, piscina... o instituto busca visitantes que possam autogestionar seu tempo na casa e dialogar com a obra da escritora.

Os residentes dispõem da Sala de Memória Casa do Sol, que nasceu da necessidade de organizar e revitalizar o acervo de Hilda Hilst e da Casa do Sol. O arquivo é composto por uma biblioteca com cerca de três mil livros, em que Hilda deixou anotações e escritos, milhares de fotografias, desenhos, plantas da casa e documentos seus e de personagens fundamentais para a história da Casa do Sol. A parte mais significativa de seu legado material, no entanto, encontra-se de posse da Universidade de Campinas, Instituto de Estudos Literários (IEL), para o qual Hilda Hilst vendeu fotografias, cartas, agendas, entre outros.

A Sala de Memória pretende ampliar o acervo a partir de campanhas para localizar itens em coleções particulares e em outros arquivos, trazendo para o IHH cópias digitalizadas. O projeto conta com espaço físico na própria casa, devidamente adequado para abrigar a Sala de Memória, atendendo às necessidades técnicas e conceituais da preservação documental. Sua chamada por ampliação do acervo é mais facilmente atendida a partir da proximidade que a Casa do Sol estabelece com o público, nesse formato de ocupação, pois muitos deles desenvolvem pesquisas a respeito de Hilda Hilst e outros produtos culturais que dialogam com o seu legado.

\section{A casa imagética}

No âmbito da crítica literária, a Casa do Sol ocupa papel de destaque na obra de Hilda Hilst, devido à recorrência e força simbólica desse espaço em seus textos. Embora este não seja o foco do presente artigo, convém abordar brevemente sua significação na obra da escritora, como forma de tornar ainda mais evidente a importância da preservação desse espaço e, por consequência, da proposta de ocupação que apresentamos aqui, afinada com conceitos relacionados à pós-modernidade, como veremos adiante.

Nas poesias reunidas em Ode remota para flauta e oboé - de Ariana para Dionísio, a casa ocupa posição de destaque:

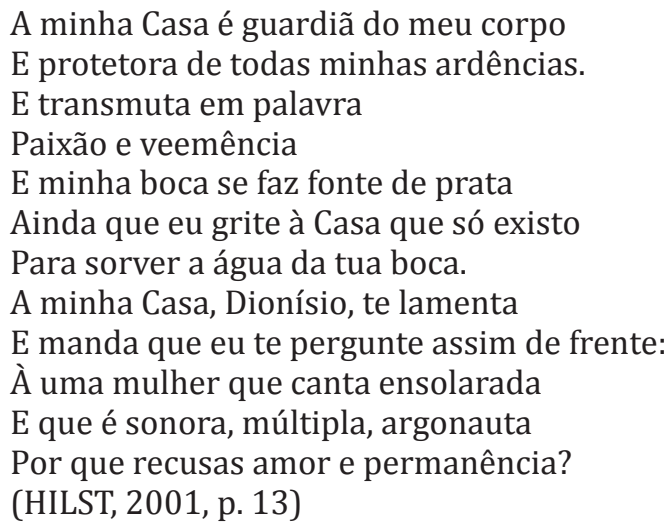

Percebe-se na poesia de Hilda Hilst, de modo geral, que a residência funciona como um centro imagético intimamente ligado ao sujeito-lírico feminino. "Guardiã”, "protetora", a casa abriga uma poeta passional, uma mulher intensa. Reflete um universo denso, fascinante, de uma mulher que "canta ensolarada", em uma inegável referência ao nome que foi dado ao lugar: Casa do Sol. Esse lugar torna-se um espelho desse ser criativo e centrado que pode, ali circunscrito, minimizar a solidão. 
A valoração da casa como retiro é sustentada por Bachelard:

E em nossos sonhos da noite, há sempre uma casa onde vivemos só. Assim o exigem certos poderes do arquétipo da casa no qual se juntam todas as seduções da vida recolhida. Todo sonhador tem necessidade de retornar à sua célula, é chamado por uma vida verdadeiramente celular (2000, p. 81).

Enquanto a própria poesia se constitui em lugar, aos poucos, o reduto imagético de Hilda Hilst, um espaço físico delimitado (a minha Casa) irá se destacar entre as odes amorosas de Hilda. Como um "segundo eu", a casa é tanto uma proteção, imagem primordial, como uma identidade, elaborada para criar para o outro, o amado, um mundo à parte, uma estrutura autônoma, repleta de referências que traduzem a personalidade do sujeito-lírico (e que podem funcionar como uma teia imaginária para aprisionar o amante - Ariana, correlata de Ariadne na mitologia, fiandeira como Arachne). Ao mesmo tempo em que seduz, a casa, cenário do encontro, é uma reserva de liberdade.

Mais uma vez, é inevitável a relação entre vida e obra. Hilda Hilst soube defender a liberdade de escolha, inclusive amorosa, como poucas de sua geração. Um universo feminino se evidencia nas imagens de Ode descontínua (...). É uma voz que demarca tanto a paixão quanto a autonomia.

É importante que aqui se entenda como feminino o que emana da poesia no plano simbólico - o plano das imagens noturnas que fazem parte de uma constelação que, por excelência, remete ao aspecto feminino da natureza, na linha de As estruturas antropológicas do imaginário, de Gilbert Durand. Nesse recorte, o poema que segue dá conta de uma perspectiva lunar da Casa do Sol:

Três luas, Dionísio, não te vejo

Três luas percorro a Casa, a minha

E entre o pátio e a figueira
Converso e passeio com meus cães

E fingindo altivez digo à minha estrela

Essa que é inteira prata, dez mil sóis

Sírius pressaga

Que Ariana pode estar sozinha

Sem Dionísio, sem riqueza ou fama

Porque há dentro dela um sol maior:

Amor que se alimenta de uma chama

Movediça e lunada, mais luzente e alta

Quando tu, Dionísio, não estás.

(HILST, 2000, p. 64).

A observação das luas remete a uma das modalidades de simbolismo temporal que podem ser identificadas na obra de Hilda Hilst. É como se a Casa erguesse uma barreira contra o tempo - esse lugar é citado na obra sempre relacionado às imagens que sugerem um tempo circular (Eterno Retorno). Para o visitante, a sensação pode ser essa mesma, a de habitar com Hilda Hilst o momento da criação, um tempo que se opõe à garra de Chronos, à aceleração cronológica.

Na solidão, Ariana se cobre com o próprio brilho, "porque há dentro dela um sol maior". A descrição reforça a importância desse retiro, enquanto os termos "cães", "pátio", "figueira" descrevem o espaço concretamente habitado, demonstrando que o limite entre a ficção e a vivência é tênue.

Hilda define assim a sua rotina na casa, em entrevista a Chiodetto (2002):

Logo ao acordar me mantinha fechada com a máquina de escrever. Só me liberava para sair de lá depois de escrever no mínimo quinhentas palavras. Alguns dias eram terríveis porque não conseguia escrever e saía do escritório só no final da tarde, para brincar com os cachorros (HILST apud CHIODETTO, 2002, p. 150).

A obstinação dos residentes em produzir faz parte do universo dessa casa que, a partir da proposta do IHH, é continuada. 
Na série de audiovisuais documentando vida e obra de Hilda Hilst (projeto Ocupação Itaú Cultural - Hilda Hilst, episódio Casa do Sol), Olga Bilenky fala sobre a recorrência da casa na obra de Hilda Hilst:

Eu, que fui tão próxima da Hilda, abro um livro dela, ela imediatamente se torna presente para mim. Ela está inteiramente na obra dela. E a vida, o cotidiano e os acontecimentos dela, estão todos descritos. Inclusive a casa, principalmente a casa é uma das imagens fortes, a casa, o pátio, tudo, é recorrente. 0 cotidiano da Hilda serviu como inspiração para toda essa obra maravilhosa, enorme que ela construiu. (informação verbal) ${ }^{3}$

A casa, e principalmente o recanto de criação do escritor, fazem parte do imaginário de muitos leitores. É como se o lugar pudesse fornecer pistas sobre o processo criativo. Chiodetto (2002) lançou uma coletânea de imagens e textos contemplando o lugar de escrita de 36 grandes nomes da literatura brasileira, incluindo Hilda Hilst. No prefácio, assinado por Kossoy, uma reflexão sobre a curiosidade e o sentido da descoberta acerca do lugar do escritor, de forma geral, pode ser colocada em diálogo com a experiência que o visitante terá na Casa do Sol.

Não temos, pois, retratos apenas; temos um percurso ficcional na trilha da criação. Uma viagem pelos mundos particulares de cada um dos personagens desse livro regida pelo fotógrafo, aqui, também, roteirista e diretor desse filme mudo que é a expressão fotográfica. Uma viagem em que participamos como leitores e espectadores; uma viagem em que presenciamos silêncios e hábitos nos recolhimentos ora sombrios, ora luminosos de seus lugares em dado momento de suas trajetórias. Uma viagem de citações múltiplas e possibilidades ilimitadas, com partida, todavia sem chegada, eterna na sua duração documental posto que interrompida pela fotografia (KOSSOY apud CHIODETTO, 2002, p. 13).

3 Ibidem, p. 3
"Uma viagem de citações múltiplas e possibilidades ilimitadas" se oferece, então, no plano real - indo além do interesse que determinado leitor pode ter diante de um livro de entrevistas e fotografias, para abarcar uma nova relação criativa com o lugar e a memória, que se estabelece na Casa do Sol.

\section{Ocupação artística}

A orientação dos gestores da Casa do Sol é de que o hóspede tenha algo a contribuir durante ou a partir de sua estadia, o que resulta em criação continuada nas mais variadas formas de expressão (teatro, dança, literatura, cinema...). Evolui-se, desse modo, da tradicional visitação para uma forma de ocupação. O visitante, liberto das relações estáticas dos museus tradicionais, assume a frente do processo.

O termo ocupação tem sido utilizado largamente para denominar as manifestações nos espaços públicos urbanos, desde as ruas, primeiramente no sentido de reivindicação de direitos pela sociedade. Nos últimos anos, com a articulação das comunidades em redes virtuais, a ocupação tornou-se mais frequente e articulada, representando causas diversas, algumas de maior abrangência, como a movimentação de julho de 2013 pela reforma política, e outras no interesse de segmentos, como o dos usuários de transporte urbano, e dos movimentos feminista, estudantil, entre outros.

As ocupações artísticas estão associadas à resistência contracultural dos anos 60, principalmente a partir da juventude estudantil de Paris, que contestavam a arte institucionalizada em museus e galerias. Por um período de tempo, um grupo de artistas reside em um local, como teatro, galeria, ou espaços alternativos, tais como fábricas, prédios residenciais, entre outros. 0 conceito se opõe ao de invasão, por ser considerado ato político, frente à especulação imobiliária no contexto 
urbano. Prédios em vias de tombamento podem vir a ser ocupados, literalmente, até a definição dos rumos de preservação; e simbolicamente, com o uso sistemático e com finalidade social advindos dessa organização.

Vistos como bens das comunidades onde se inserem, esses espaços ocupados passam a ser, desse modo, legítimo patrimônio, não mais restrito ao sentido material, mas ao imaterial que perpassa a memória e as relações humanas possibilitadas nessas circunscrições. Não mais uma visitação passiva, ocupar significa tomar para si - fazer uso. A ocupação de espaços culturais, pensada democraticamente, se torna uma via de sustentação para a comunidade, nos princípios da economia criativa.

No Brasil, a ocupação conhecida como Centro Cultural Ouvidor 63, cujo nome contempla o endereço do prédio de 13 andares localizado no Centro de São Paulo, é considerada a maior da América Latina. Em maio de 2014, um grupo de artistas se apropriou do prédio pertencente ao Estado. A reintegração de posse tem sido tentada por meio de leilões, mas até o momento (outubro de 2017) não houve interesse de compra.

No local, os ocupantes realizam manutenções possíveis e promovem festas, bazares e oficinas artísticas a fim de obterem recursos para a manutenção da proposta. Algumas iniciativas educativas envolvem promoções gratuitas para comunidades pobres, como forma de contrapartida. Segundo reportagem do Estado de São Paulo: "Os moradores do endereço não são sem-teto. Acreditam que o local deve funcionar como uma usina de criação artística, nas mais diversas áreas, sem liderança, tudo horizontal, tudo tratado em assembleias, tudo de modo colaborativo".

O termo ocupação foi apropriado, mais recentemente, pelas instituições, vide a série Ocupação Itaú Cultural, que abrange grandes nomes das artes, incluindo Hilda Hilst na área da Literatura, e que se constitui de exposições e audiovisuais.
Um prédio tombado, como é o caso do patrimônio que foi habitado por Hilda Hilst, é um espaço público, não necessariamente um lugar. Ainda que carregada de sentido material (os objetos de pertença, os cômodos), a propriedade regulada nos moldes de uma museologia convencional, com horários de visitação, guias, porteiros, mantém uma barreira de impessoalidade e uniformidade no trato. É preciso transcender a mera circulação e estabelecer relações de sentido para converter espaço em lugar.

Na contemporaneidade, a tendência de formação de não lugares foi apontada por Augé (2007). No uso dos aparelhos culturais, muitas vezes o que se experiencia é a relação solitária com o objeto, e breve, de passagem. A ação racional se impõe e o indivíduo é subjugado à condição de espectador, numa visitação padronizada: "O não lugar é o espaço dos outros sem a presença dos outros, o espaço constituído em espectáculo” (AUGÉ, 1994, p. 167).

A nova museologia, a partir dos anos 1970, sugere que os museus deixem de ser coletores passivos. São programadas atrações que sensibilizam e permitem a criação pessoal de sentido: os visitantes se tornam atores das atividades museológicas e as populações representadas se veem em sua dinâmica histórica, que contempla presente e futuro, não mais um passado estanque. Nessa perspectiva podemos inserir o programa Residência Criativa.

A possibilidade de habitar temporariamente o ambiente em que viveu a escritora, a chance de ter contato com seu acervo e objetos pessoais, transcende a ideia de visitante passivo. Há uma imersão na casa, por períodos de pelo menos quatro dias, o que aproxima o visitante das rotinas que faziam parte da vida da escritora, desde o cuidado com os cães (que chegaram ao número de 60), aos passeios noturnos pelas alamedas.

Atividade em si transformadora de condutas, tanto individuais como coletivas, o turismo cultural, na perspectiva motivada pela Casa do Sol, é 
provocador: aprofunda a experiência. Residir (criativamente) é preservar em plenitude: "Morar é narrar. Fomentar ou restaurar esta narratividade, é também uma tarefa de reabilitação" (CERTEAU, 1987, p. 84).

\section{Testemunhos}

Para os criativos, estar na Casa do Sol é uma oportunidade inspiradora. Entrevistas no blog do Instituto Hilda Hilst dão conta desses estímulos. Na época em que trabalhava na tradução do livro Com meus olhos de cão, Adam Morris fez parte do programa. Viveu na Casa do Sol durante quinze dias, período em que tentou "entrar na mente da autora" e habitá-la de qualquer maneira possível. "Quase todos os dias eu ia ler debaixo da figueira onde Hilda também costumava ler, e à noite ficava na mesa onde ela escrevia e estudava", conta Morris, em entrevista.

O pesquisador teve a oportunidade de manusear os livros da biblioteca de Hilda, além dos manuscritos da Unicamp.

Os diretores do Instituto eram amigos pessoais da escritora, e a ideia é continuar na tradição que Hilda estabeleceu lá na Casa - a vida coletiva entre intelectuais. Eles me contaram coisas sobre ela que ajudaram muito com a tradução, coisas que ela dizia, as relações que tinha, e também indicações sobre os estudos e interesses dela. (MORRIS, 2015)

Outra residente, a tradutora Dinaura Julles relata a dimensão da experiência:

A residência na Casa do Sol - Instituto Hilda Hilst - deveria ter sido isso: uma residência criativa, dedicada à tradução dos poemas 'Do Desejo' e 'Da Noite'. Mas acabou se revelando um profundo mergulho. Mergulho nos quadros de Olga Bilenky, gentil e inspirada anfitriã; no universo de Hilda Hilst, a Casa, os cachorros, os altares, os livros, nesse mundo meio terra e meio magia, em que habitam avencas e figueiras. 0 erotismo de
'Do Desejo' e a densidade de 'Da Noite' estão nas sutilezas dos detalhes da Casa do Sol, nos reflexos dos espelhos, nos olhares vivos das fotografias, nos movimentos implícitos das mandalas. Mais que uma residência, uma profunda experiência. A tradução dos poemas, objetivo principal, acabou sendo uma consequência. Que ela ecoe e reverbere em outras línguas (JULLES, 2015).

Além da dimensão criativa possibilitada pela experiência, é interessante perceber sua importância como representativa de uma relação temporal diferenciada, como veremos adiante. Assim como a obra poética de Hilda Hilst sugere temporalidades diversas, o desejo de estar entre os pertences da escritora contraria o ritmo ditado pela economia nas grandes cidades.

O relato de Juarez Guimarães, residente contemplado pela Funarte para a criação de obra literária na Casa do Sol, dá conta dessas particularidades temporais:

Nesses intensos dias de residência, pesquiso o acervo do Instituto Hilda Hilst tendo as preciosas companhias de Daniel Bilenky Mora Fuentes, Olga Bilenky e Jurandy Valença, parte da família eletiva de Hilda Hilst, que perpetuam o projeto da Casa do Sol, convertida no Instituto que ela tanto idealizou ao lado de Mora Fuentes. Esses dias de pesquisa para a escrita do meu romance 'A Casa da Senhora H' têm sido incríveis: visitamos cartas, objetos, papéis, textos inéditos, adornos, anotações, fotografias com o objetivo de fazer a arqueologia de Hilda e outros personagens que habitaram esta casa tão singular. Procuro rastros e pistas desse cotidiano, de uma Casa sem tempo, pois o relógio avisa 'É mais tarde do que supões...' Esbarro em intimidades, banalidades, dificuldades, prazeres, vestígios de um presente que só existe aos fragmentos (GUIMARÃES, 2012).

O contato com a vida "profana" de Hilda Hilst, no sentido de cotidiana, "dessacraliza" o autor, ou seja, possibilita compreendê-lo em sua dimensão humana mais ampla. Essa relação, que já não contempla apenas obra e vestígios canônicos, mas "intimidades, banalidades e dificuldades", parece ser um dos mais significativos diferenciais da abertura da Casa do Sol. 


\section{Patrimônio imaterial e sociedades pós-modernas}

O projeto Residência Criativa se insere na vanguarda entre as iniciativas envolvendo patrimônio e memória, na linha da nova museologia: "O museu pode ser agente de mudança social, de regeneração e de 'empowerment' (empoderamento) das populações, na medida em que se torne mais consciente da comunidade que o rodeia e se torne um efetivo espaço de congregação para essa comunidade" (cf. DUARTE, 2013, p. 113).

Que tempo seria esse em que se inscreve uma nova relação com a memória, quase que possibilitando frear a roda acelerada do desenvolvimento a qualquer custo? Segundo Maffesoli, em $O$ instante eterno, a pós-modernidade pode ser lida como a pluralização do mundo, gerando identificações múltiplas.

Além da aparente uniformização 'mundializante', é surpreendente constatar a multiplicidade de atividades, de centros de interesse, de mestiçagem de toda ordem, de diversos sincretismos religiosos, filosóficos, musicais. Coisas que constituem a vida em sua diversidade, coisas que voltam a dar à vida um lugar central nas sociedades (MAFFESOLI, 2003, p. 10).

Tal pluralidade justifica que os museus transformem a sua forma de atuação, não mais trabalhando, necessariamente, para abranger as massas, mas oferecendo experiência de qualidade para públicos específicos, uma vez que há perfis para os mais variados segmentos.

Ainda em Maffesoli:

Estamos deslizando de uma concepção de mundo 'egocentrada' para outra, 'locuscentrada'. Na modernidade que se acaba, a primazia é do indivíduo racional numa sociedade contratual; na pós-modernidade nascente, o que está em jogo são grupos, 'neotribos', que investem em espaços específicos e se acomodam a eles. No drama moderno há a pretensão otimista da totalidade: minha, do mundo, do Estado. No trágico pós-moderno, o foco é a 'interidade', perda do pequeno eu em um 'em Si' mais vasto, que contempla a alteridade natural e social (2003, p. 8).
Deslocando o foco do social para os estudos da área de Turismo, essa tendência se confirma. Segundo Gastal:

O turismo da Modernidade segue as lógicas do período: só a produção em grande quantidade e em série resultará em sucesso financeiro. A isso se denominou turismo de massa. A Pós-Modernidade imporá a lógica da qualidade e da segmentação, materializada em produtos turísticos com performances que busquem atender às novas demandas sociais (e mercadológicas), carentes deste diferencial $(2004$, p. 2).

Paulatinamente, o patrimônio de Hilda Hilst se mantém e se recria por meio de um programa que se diferencia da lógica das massas, mas se mostra eficiente dentro de seus propósitos. Gastal destaca que o turista contemporâneo prefere deslocar-se sozinho ou em pequenos grupos, com pouca bagagem, e prioriza a experiência única e pessoal, de relacionar-se com as culturas visitadas nos seus cotidianos.

Ou seja, este viajante quer construir seus próprios significados em relação aos lugares e às pessoas, buscando ultrapassar a caricatura e os estereótipos em relação às nacionalidades. A exemplo de outras vivências, o viajante prefere a intensidade ao extensivo, quer em relação ao tempo (os deslocamentos são mais curtos) quer em relação ao espaço (visitam-se menos lugares) (GASTAL, 2004, p. 12).

O movimento de abertura da Casa do Sol, e suas vertentes de criação continuada na fruição do patrimônio cultural são coerentes com os desejos desse novo sujeito, que faz ressonância com os postulados da Estética Relacional.

Bourriaud compreende o artista contemporâneo como aquele que já não se volta somente a grandes utopias, mas atua a partir de microutopias funcionais dentro do corpo social. Dentre essas microutopias é possível pensar na desaceleração do tempo que se estabelece no microcosmo da Casa do Sol, como em alguns espaços de arte que privilegiam o relacional 
ante à mera contemplação e, assim, "(as artes contemporâneas) podem gerar durações com um ritmo contrário ao das durações que ordenam a vida cotidiana, favorece um intercâmbio humano diferente das 'zonas de comunicação' que nos são impostas." (2009, p. 23)

Maffesoli distingue modernidade e pós-modernidade, essencialmente, pela relação com o tempo:

No ano 1000, o abade Gerber, conhecido como Papa Silvestre II, inventou esse relógio que submeteu o tempo à medida. 0 que serviu, também, de fundamento à História e à Filosofia. 'Sentimento histórico do universo', observa a respeito 0 . Spengler, reduzindo progressivamente a multiplicidade das culturas e preparando o totalitarismo do Um e do mercado ou, o que vem a ser o mesmo, do racionalismo. Os bem intencionados, hoje em dia, chamaram a isso 'globalização' ou 'mundilização'. Sem se dar conta, desconectados como estão da surrealidade soecietal, de que tudo isso é pura abstração, limitada à ordem econômica ou política (2003, p. 9).

A ruptura com o "tempo da máquina" se dá a partir de uma consciência da fragilidade dos contratos que até então regiam os projetos de vida. Essa noção possibilita o presenteísmo, ainda segundo o sociólogo:

Do cotidiano, em que há pouca terra incógnita, temos a tendência a não reter mais que o anedótico, ou o superficial. (...) De fato, a velocidade, sob suas diversas modulações, foi a marca do drama moderno. (...) De modo contrário, hoje vemos despertar o elogio da lentidão, incluindo a ociosidade. A vida não é mais que a concatenação de instantes imóveis, de instantes eternos, dos quais se pode tirar o máximo gozo (MAFFESOLI, 2003, p. 7-8).

Por essas perspectivas, a relação obra de arte-espectador sofre uma transformação. 0 público já não observa a obra do exterior, mas passa a integrá-la, inserindo-se no coletivo, criando uma "comunidade com carácter temporário", que condiz com a convivência possibilitada pela abertura da Casa do Sol. Essas oportunidades em que a participação se torna su- perior à contemplação podem assumir caráter emancipatório para seus públicos.

Uma obra aberta necessita do outro para se completar. O objetivo da Estética Relacional não é o convívio, mas o produto desse convívio. Ainda em Bourriaud, é possível refletir sobre as concepções acerca do caráter solitário do artista. O projeto de "retiro criativo", como vivido por Hilda Hilst, demonstrava ter dimensões sociais já no tempo de sua produção.

Para Bourriaud, a ideologia dominante prefere a imagem do artista solitário, distanciado do mundo para criar. É mais fácil quando a arte se distancia da sua vocação política, mas essa condição estaria no cerne da atividade:

A formação de relações de convívio é uma constante histórica desde os anos 1960. A geração dos anos 1990 retoma essa problemática, mas sem o problema da definição de arte, central para as décadas de 1960 e 1970 . A questão não é mais ampliar os limites da arte, e sim testar sua capacidade de resistência dentro do campo social global (2009, p. 43).

A perspectiva relacional, ainda segundo o autor, esbarra em dificuldades de legitimação, pois está cada vez menos inserida em um sistema ideológico tradicional. Seu afastamento, seu caráter livre, fragmentário, se desliga na medida do possível da engrenagem globalizante.

Maffesoli identifica nas sociedades pós-modernas um novo sujeito, que rompe com o princípio de individuação na possibilidade de comunicação não verbal, quando o laço social se verifica no ímpeto de estar junto, seja dançando uma mesma música, seja interagindo em rede, compartilhando (2001, p. 113).

Não é por acaso que o sistema de divulgação do programa Residência Criativa se dá, justamente, nas redes sociais - com ênfase ao Facebook e ao Tumblr. Essas redes têm a capacidade de agregar pessoas por afinidades, e a divulgação atinge exatamente o público-alvo. 
Estar na casa motiva o compartilhamento da experiência, típico da vida mediada pela tecnologia. $\mathrm{O}$ simples fato de visitar, fotografar e compartilhar as imagens e, provavelmente, os conteúdos experienciados em um lugar como a Casa do Sol, estimula a cadeia cultural - atrai mais leitores para a obra do que Hilda Hilst (que se dizia muito frustrada com a recepção do público ao longo de sua vida) poderia supor.

Essa dinâmica construção de sentido põe a literatura de Hilda Hilst em movimento. Já não se trata de um passado articulado para se transformar em memória, mas a geração de novas experiências estéticas, de troca e ressignificação a partir de uma relação com essa memória.

Outra característica comportamental importante no contemporâneo é a ênfase à presentificação. Conhecer a oportunidade e, logo, estar na casa do autor (possibilitado também pelas novas facilidades de mobilidade, como voos mais acessíveis, por exemplo), corresponde à forma de fruição desses tempos. Vive-se a experiência tátil, o contato com a obra em seu lugar de criação e se pode dar continuidade a essa tessitura do sentido pelo viés da comunicação, o que contribui para a difusão do legado cultural.

\section{Conclusão}

Tanto Bourriaud como Maffesoli tendem a sobrepor o desejo de uma nova sociabilidade aos apelos contundentes à sociedade ainda regrada pelo capital, que tem na palavra "democracia" um termo quase vazio, quando o pensamento se volta para as desigualdades sociais e para as reais possibilidades de acesso a esses espaços onde a arte e a cultura se disponibilizam ao compartilhamento.

Na perspectiva do "espírito de uma época", no entanto, segue válida a aproximação da experiência desenvolvida na Casa do Sol à linha desses pensadores das sociedades pós-modernas. O plural estabelecido também é relevante: a pós-modernidade no viés desses autores é, com justiça, caracterizada como condição 'de sociedades', não 'da sociedade', uma vez que não há como totalizar o humano frente a condições tão díspares, não apenas nos contextos socioeconômicos diversos, mas mesmo no cerne de uma única nação, como no Brasil, onde coexistem com o avanço tecnológico, modos de vida correspondentes a temporalidades diversas, muitas vezes por entraves culturais. A pós-modernidade está mais para uma tomada de consciência do ritmo imposto pelas sociedades globalizadas, do que para um tempo cronológico.

A vivência na Casa do Sol permite, de certa forma "habitar o tempo" de Hilda Hilst, no contato com vestígios materiais e o que os transcende, uma vez que a casa comporta o convívio com pessoas de seu círculo e profundos conhecedores de seu acervo. $\mathrm{O}$ acesso à cultura e o fomento de novas produções culturais em diálogo com a vasta e versátil obra de Hilda Hilst são os bens gerados 'a priori' pela iniciativa.

No contexto da pós-modernidade, realiza-se uma microutopia, a de habitar melhor o mundo, ao invés de pretender refazê-lo. Dessa forma, o lugar de memória promove o encontro, a vivência e a elaboração coletiva de sentido. A casa oferece uma oportunidade de tornar presentificado o caráter pretérito do museu: "O objeto é restituído a um não tempo antropológico no qual a alteridade pode, mais uma vez, ser experimentada como se estivesse intacta e completa", como pontua Andermann (2014, p. 87), propiciando a interação do visitante de um modo arrebatador.

O desafio é entender melhor esse modelo de uso do patrimônio de escritor para que possa ser continuado posteriormente à atual geração ligada ao projeto, uma vez que a ideia se mantém intimamente vinculada à figura de Olga Bilenky - seu tempo, sua disponibilidade afetiva para com o visitante e suas questões.

O envolvimento pessoal (que é a essência da Residência Criativa na Casa do Sol) pode vir a ser seu ponto fraco em termos de replicação para 
outras casas de autor ou artista, uma vez que não se tem uma gestão profissionalizada e sistemática, mas é justamente nessa espontaneidade que reside o grande atrativo do local.

Considerado o pioneirismo da Residência Criativa no trato com o patrimônio imaterial, e a dimensão das experiências relatadas numa primeira coleta, evidencia-se a necessidade de amparar, pelo viés da pesquisa, o melhor entendimento desse modelo e sua possível aplicação em outros contextos, de forma que se garanta a preservação, divulgação e apropriação cultural a partir da ocupação de residências como essa.

Questões relativas às formas de consumo cultural destes tempos serão aprofundadas, contemplando a economia criativa e o possível viés lúdico já abordado considerando, sempre, as particularidades de cada caso, uma vez que a pessoalização no trato com o acervo e as memórias, a singularidade da experiência na convivência e no diálogo constituem, de fato, o maior patrimônio da Casa do Sol.

\section{Referências}

ANDERMANN, Jens. A optica do Estado: visualidade e poder na Argentina e no Brasil. Rio de Janeiro: UERJ, 2014

AUGÉ, Marc. Le sens des autres. Actualité de l'anthropologie. Paris: Fayard, 1994.

BACHELARD, Gaston. A poética do espaço. São Paulo: Martins Fontes, 2000.

BOURRIAUD, Nicolas. Estética relacional. São Paulo: Martins Fontes, 2009.

CERTEAU, Michel de. Les revenants de la ville. Traverses, 40, abril de 1987.

CHIODETTO, Eder. O lugar do escritor. São Paulo: Cosac \& Naify, 2002.

DUARTE, Alice. Revista Eletrônica do Programa de Pós-Graduação em Museologia e Patrimônio (PPG-PMUS). Rio de Janeiro: Unirio. v. 6, n. 1, p. 99-113. 2013. Disponível em: <http://revistamuseologiaepatrimonio.mast.br/index.php/ppgpmus/article/ viewFile/248/239>. Acesso em: 01nov. 2017.
DURAND, Gilbert. As estruturas antropológicas do imaginário: introdução à arquetipologia geral. São Paulo: Martins Fontes, 2002.

GASTAL, Susana. O tempo na tessitura pós-moderna: entre o museu acontecimento e o souvenir-memória. Congresso Intercom - NP 19, Anais, Porto Alegre, 2004. Disponível em: $<$ http://cienciaparaeducacao.org/eng/publicacao/gastal-susana-o-tempo-na-tessiturapos-moderna-entre-o-museu-acontecimento-e-o-souvenir-memoria-in-intercom-20042004-porto-alegre-anais-intercom-2004/>. Acesso em: 01 nov. 2017.

GUIMARÃES, Juarez. Depoimento ao Instituto Hilda Hilst. Campinas: IHH, 2012. Disponível em: <http://www.hildahilst.com.br/blog>. Acesso em: 27 out. 2017.

HILST, Hilda. Júbilo, memória, noviciado da paixão. São Paulo: Globo, 2001.

JULLES, Dinaura. Depoimento ao Instituto Hilda Hilst. Campinas: IHH, 2015. Disponível em: <http://www.hildahilst.com.br/blog>. Acesso em: 27 out. 2017.

MAFFESOLI, Michel No fundo das aparências. Petrópolis: Vozes, 1996.

O instante eterno: o retorno do trágico nas sociedades pós-modernas. São Paulo: Zouk, 2003.

MORRIS, Adam. Depoimento ao Instituto Hilda Hilst. Campinas: IHH, 2015. Disponível em: <http://www.hildahilst.com.br/blog>. Acesso em: 01 nov. 2017.

OCUPAÇ̃̃O ITAÚ CULTURAL, 2015. Disponível em: <https://www.youtube.com/ watch?v=OAPr0I241PA>. Acesso em: 25 out. 2017

ROSENFELD, Anatol. Hilda Hilst, poeta, narradora, dramaturga. São Paulo: 1970 Disponível em: <http://www.angelfire.com/ri/casadosol/criticaar.html>. Acesso em: 01 nov. 2017.

VEIGA, Edison. Ouvidor 63, há 3 anos nas mãos de artistas. O Estado de S. Paulo, 29 de abril de 2017. Disponível em: <http://sao-paulo.estadao.com.br/noticias/geral,ouvidor63-ha-3-anos-nas-maos-de-artistas,70001756912>. Acesso em: 26 out. 2017.

Recebido em 25/01/2017.

Aceito em $03 /$ 